\title{
Características de doce em massa de umbu verde e maduro e aceitação pelos consumidores
}

\author{
Maria Lúcia Almeida Martins(1), Soraia Vilela Borges( ${ }^{(2)}$, Rosires Deliza( ${ }^{(3)}$, Fernanda Travassos de Castro(1) \\ e Nilton de Brito Cavalcante ${ }^{(4)}$
}

\begin{abstract}
(1)Universidade Federal Rural do Rio de Janeiro, Dep. de Tecnologia de Alimentos, Km 47 da Antiga Rodovia Rio-SP, CEP $23851-970$ Seropédica, RJ. E-mail: luciaalmei@yahoo.com.br, fertcastro@bol.com.br (2)Universidade Federal de Lavras, Dep. de Ciência dos Alimentos, Campus Universitário, CEP 372000-000 Lavras, MG. E-mail: sborges@ufla.br (3)Embrapa Agroindústria de Alimentos, Av. das Américas, no 29.501, Guaratiba, CEP 23020-470 Rio de Janeiro, RJ. E-mail: rodeliza@ctaa.embrapa.br (4)Embrapa Semi-Árido, BR 128, Km 152, Zona Rural, CEP 56300-970 Petrolina, PE. E-mail: nbrito@cpatsa.embrapa.br
\end{abstract}

\begin{abstract}
Resumo - O objetivo deste trabalho foi avaliar formulações de doces, em massa de umbu verde e maduro, quanto às características físico-químicas e físicas, e quanto à aceitação pelos consumidores residentes no Rio de Janeiro. Quatro formulações de doces foram processadas para polpa de umbu verde: F1, 0,3\% de goma xantana; F2, $5 \%$ de xarope de glicose e $0,3 \%$ de goma xantana; $\mathrm{F} 3,0,5 \%$ de amido modificado; $\mathrm{F} 4,5 \%$ de xarope de glicose e $0,5 \%$ de amido modificado; e quatro formulações para polpa de umbu maduro: $\mathrm{F} 1$, apenas correção de pH; $\mathrm{F} 2,0,5 \%$ de pectina; $\mathrm{F} 3,0,3 \%$ de goma xantana; $\mathrm{F} 4,5 \%$ de xarope de glicose e $0,5 \%$ de amido modificado. Foram avaliadas as seguintes características físico-químicas e físicas: sólidos solúveis, acidez titulável, pH, açúcares redutores e não redutores, atividade de água, cor, firmeza e adesividade. Cinqüenta e seis consumidores avaliaram as formulações, por meio de escala hedônica estruturada de nove pontos. As formulações F2 apresentaram maior firmeza. Os consumidores atribuíram notas superiores a seis na escala utilizada, para todas as formulações, o que indica aceitação dos produtos.
\end{abstract}

Termos para indexação: Spondias tuberosa, aditivo alimentar, análise sensorial, processamento de frutas, consumidor.

\section{Characteristics of green and ripe umbu marmalades and acceptance by consumers}

\begin{abstract}
The objective of this work was to evaluate green and ripe umbu marmalade formulations, in relation to physicochemical and physical characteristics, and regarding Rio de Janeiro consumers' acceptance. Four marmalade formulations were processed for green umbu pulp: F1, $0.3 \%$ xanthan gum; F2, 5\% glucose syrup and $0.3 \%$ xanthan gum; $\mathrm{F} 3,0.5 \%$ modified starch; $\mathrm{F} 4,5 \%$ glucose syrup and $0.5 \%$ modified starch; and four formulations for ripe umbu pulp: F1, only pH correction; F2, $0.5 \%$ pectin; F3, $0.3 \%$ xanthan gum; F4, 5\% glucose syrup and $0.5 \%$ modified starch. The physicochemical and physical characteristics evaluated were: soluble solids, titrable acidity, $\mathrm{pH}$, reducing and nonreducing sugars, water activity, color, firmness and adhesiveness. Fifty-six consumers evaluated the formulations, using nine-point structured hedonic scale. The formulations F2 presented higher firmness. Consumers gave notes higher than six in the used scale, which indicates the approval of the products.
\end{abstract}

Index terms: Spondias tuberosa, food additives, sensory analysis, fruit processing, consumer.

\section{Introdução}

O umbu (Spondias tuberosa Arruda Câmara) é uma fruta de grande importância econômica para o SemiÁrido nordestino, pois sua polpa é aproveitada para a fabricação de doces e geléias, entre outros produtos (Cavalcanti et al., 2000; Pinto et al., 2001; Policarpo, 2003a). De acordo com o IBGE (2003), a produção nacional de umbu foi de 9.132 toneladas, e o Município de Juazeiro, BA, foi o principal produtor nacional (654 toneladas).
$\mathrm{Na}$ época da safra, que vai de dezembro a março, há fartura de frutos e, durante a colheita, ocorre perda considerável de umbu maduro por ser bastante perecível. Como conseqüência, surgiu a necessidade do desenvolvimento de tecnologia apropriada para doces de polpa de umbu verde, para o aproveitamento de toda a produção e diminuição de perdas para o produtor, além da agregação de valor aos produtos derivados (Policarpo et al., 2003a). A agregação de valor aos produtos contribui para o fortalecimento da agricultura familiar e do desenvolvimento regional. 
Os doces em massa são resultantes do processamento adequado das partes comestíveis dos vegetais, adicionados de açúcares, água, pectina $(0,5$ a $1,5 \%)$, ajustador de $\mathrm{pH}$ ( 3 a 3,4), além de outros ingredientes e aditivos permitidos até alcançar consistência adequada, assegura estabilidade ao produto. Após o processamento, os doces devem ser devidamente embalados e armazenados nas condições ambientais (Jackix, 1988; Abia, 2001). Albuquerque (1997) relata que fatores intrínsecos, como o grau de esterificação da pectina e o $\mathrm{pH}$ do doce, influem no processamento. Além disso, fatores extrínsecos como: pré-processamento da fruta, temperatura de cocção, tamanho da embalagem, tempo e temperatura de geleificação, além da ordem na colocação dos ingredientes afetam o processo de fabricação de geléias e doces e, por conseguinte a qualidade do produto final.

A polpa de umbu é caracterizada pela alta acidez, que causa, durante o armazenamento, elevada sinérese no doce. A redução da acidez pode contribuir para a redução da sinérese, e o emprego de agentes com propriedade de evitar este fenômeno, sem prejudicar as características sensoriais, pode ser alternativa interessante para melhorar as características do produto final. Fennema (1993), Campos \& Candido (1995), Mao et al. (2001) e Renard et al. (2006) reportaram que produtos como pectina, amido modificado e goma xantana tiveram a capacidade de reter água, poder geleificante e espessante e são, portanto, indicados para a fabricação do doce de umbu. A correção de $\mathrm{pH}$ e adição de pectina resultou em doces de umbu de polpa verde com reduzida sinérese, ao longo do armazenamento por 90 dias (Policarpo, 2002). A adição de xarope de glicose, em concentração de até $15 \%$ dos açúcares totais, melhora a qualidade do doce, confere aparência mais brilhante ao produto, retarda a cristalização da sacarose e impede a sinérese, além de reduzir o nível de doçura (Jackix, 1988).

A introdução de aditivos em formulações, com o intuito de melhorar alguma propriedade, pode interferir negativamente em outras, principalmente no sabor e na cor, portanto, é necessário avaliar o produto em relação às características sensoriais e aceitação do consumidor. Nesse sentido, a análise sensorial é um importante instrumento analítico para a seleção da formulação mais adequada, controle da qualidade e outras atividades, tais como: avaliação do produto após alteração de formulação, para a redução de custos, alteração de parâmetros de processo e formulação (Stone \& Sidel, 2004).

Doces em pasta e corte são bastante populares nas diversas regiões do Brasil (Garcia, 2002), e o doce de umbu é, particularmente, muito apreciado por indivíduos da Região Nordeste, que têm o hábito de consumir a fruta e seus produtos processados. Tal doce não é conhecido pela população da Região Sudeste, porém, se apresentar características sensoriais adequadas, pode ser aceito por essa população.

O objetivo deste trabalho foi avaliar formulações de doces de umbu verde e maduro, quanto às características físico-químicas e físicas, e quanto à aceitação pelos consumidores residentes no Rio de Janeiro.

\section{Material e Métodos}

Foram utilizados frutos verdes e maduros de umbu, fornecidos pela Embrapa Semi-Árido, em Petrolina, PE, enviados congelados para a UFRRJ, Seropédica, RJ. Os frutos foram selecionados, branqueados para inativação da enzima peroxidase $\left(100^{\circ} \mathrm{C}\right.$, por $\left.3 \mathrm{~min}\right)$ e despolpados em despolpadeira elétrica. A polpa foi acondicionada em sacos de polietileno de baixa densidade, selados e congelados para processamento do doce de umbu.

Quatro formulações de doces em massa foram processadas para a polpa de umbu verde: F1, 0,3\% de goma xantana; F2, 5\% de xarope de glicose e $0,3 \%$ de goma xantana; F3, 0,5\% de amido modificado; F4, 5\% de xarope de glicose e $0,5 \%$ de amido modificado. Também foram processadas quatro formulações para a polpa de umbu maduro: $\mathrm{F} 1$, apenas correção de $\mathrm{pH} ; \mathrm{F} 2,0,5 \%$ de pectina; F3, $0,3 \%$ de goma xantana; $F 4,5 \%$ de xarope de glicose e $0,5 \%$ de amido modificado.

A relação polpa/açúcar foi de 1:1, em ambos os doces, e o $\mathrm{pH}$ das polpas foi corrigido com $\mathrm{CaCO}_{3}$, para conferir geleificação adequada da pectina, conforme Jackix (1988). A polpa foi descongelada em ambiente refrigerado, no dia anterior ao processamento. Os ingredientes foram pesados em balança analítica ou semi-analítica, conforme a quantidade, e adicionados em panela de aço inoxidável. Sob aquecimento e agitação manual, foram concentrados ao grau brix desejado e acondicionados a quente, em embalagens de polipropileno, que foram fechadas e resfriadas sob água corrente. Os doces foram armazenados sob refrigeração, para análises sensoriais, físico-químicas e físicas.

Foram realizadas as seguintes análises, em triplicata, das formulações de doces de umbu verde e maduro, conforme a Association of Official Analytical Chemists (1992): sólidos solúveis, por refratometria; acidez titulável, por titulação com solução de $\mathrm{NaOH}$, em presença de fenolftaleína; e $\mathrm{pH}$ por potenciometria; açúcares redutores e não redutores, por titulometria com reagente de Fehling. A atividade de água foi medida no medidor de atividade de água Aqualab, a $25^{\circ} \mathrm{C}$. Os parâmetros de cor foram medidos em espectrofotômetro, com geometria especular incluída, 
tendo-se utilizado iluminante $\mathrm{D} 65 / 10^{\circ}$, e os resultados foram expressados como a média de oito determinações. A firmeza e adesividade foram medidas em texturômetro TA-XT2i, com a célula P/45 $\phi$ e velocidades de pré-teste, teste e pós-teste de $2 \mathrm{~mm} \mathrm{~s}^{-1}, 1 \mathrm{~mm} \mathrm{~s}^{-1}$ e $10 \mathrm{~mm} \mathrm{~s}^{-1}$, respectivamente, aplicadas em amostras de $1 \mathrm{~cm}^{3}$. Os resultados foram submetidos à análise de variância ANOVA, e as médias foram comparadas pelo teste de Tukey, a 5\% de probabilidade (Pimentel-Gomes, 1999).

As formulações de doce de umbu verde e maduro foram avaliadas quanto à aceitação, de acordo com Meilgaard et al . (1999), tendo-se utilizado a escala hedônica de nove pontos, em que: 1 - desgostei extremamente; 2 - desgostei muito; 3 - desgostei moderadamente; 4 - desgostei ligeiramente; 5 - não gostei nem desgostei; 6 - gostei ligeiramente; 7 - gostei moderamente; 8 -gostei muito; 9 -gostei extremamente. Cinqüenta e seis consumidores foram convidados a participar da avaliação das formulações de doces de umbu verde e maduro. $O$ intervalo entre a avaliação dos doces de umbu verde e maduro foi de 10 dias. Dados sobre o conhecimento e o consumo de umbu e derivados foram coletados, como: conhecimento sobre a fruta, sobre produtos derivados, freqüência de consumo e local de consumo. As amostras foram cortadas em cubos de $2 \mathrm{~cm}$ e apresentadas de forma monádica, em pires brancos codificados com número de três dígitos. Os testes foram realizados nas cabines individuais do Laboratório de Análise Sensorial e Instrumental da Embrapa Agroindústria de Alimentos, sob luz branca, e a ordem de apresentação das amostras foi balanceada segundo MacFie et al. (1989). Os resultados foram submetidos à análise de variância ANOVA, e as médias foram comparadas pelo teste de Tukey, a 5\% de probabilidade (Pimentel-Gomes, 1999). Histogramas de distribuição de frequiência de notas de preferência, atribuídas pelos consumidores para as diferentes formulações de doce de umbu verde e maduro, foram elaborados.

\section{Resultados e Discussão}

Não foram observadas diferenças significativas, entre as médias das formulações de doce em massa de umbu verde, para as características físico-químicas e físicas, com exceção da firmeza e dos açúcares redutores na formulação F2 (Tabela 1). A adição de xarope de glicose

Tabela 1. Características físico-químicas e físicas e notas de aceitação, atribuídas pelos consumidores às formulações de doces em massa de umbu verde e maduro ${ }^{(1)}$.

\begin{tabular}{|c|c|c|c|c|}
\hline Característica & $\mathrm{F} 1$ & $\mathrm{~F} 2$ & F3 & $\mathrm{F} 4$ \\
\hline & \multicolumn{4}{|c|}{ Doce em massa de umbu verde } \\
\hline $\mathrm{pH}$ & $3,80 \pm 0,57 \mathrm{a}$ & $3,83 \pm 0,67 \mathrm{a}$ & $3,54 \pm 0,09 \mathrm{a}$ & $3,45 \pm 0,02 \mathrm{a}$ \\
\hline Acidez titulável (\% em ácido cítrico) & $0,42 \pm 0,04 \mathrm{a}$ & $0,44 \pm 0,02 \mathrm{a}$ & $0,33 \pm 0,05 \mathrm{a}$ & $0,43 \pm 0,02 \mathrm{a}$ \\
\hline Sólidos solúveis totais $\left({ }^{\circ} \mathrm{Brix}\right)$ & $72,50 \pm 0,50 \mathrm{a}$ & $72,33 \pm 0,58 \mathrm{a}$ & $71,67 \pm 1,53 a$ & $72,67 \pm 1,89 a$ \\
\hline Atividade de Água (aw) & $0,82 \pm 0,01 \mathrm{a}$ & $0,82 \pm 0,02 \mathrm{a}$ & $0,83 \pm 0,02 \mathrm{a}$ & $0,81 \pm 0,02 \mathrm{a}$ \\
\hline Açúcares não redutores (\%) & $44,72 \pm 3,60 \mathrm{a}$ & $47,99 \pm 4,40 \mathrm{a}$ & $44,54 \pm 4,34 \mathrm{a}$ & $40,23 \pm 3,27 a$ \\
\hline Açúcares redutores & $27,55 \pm 3,60 \mathrm{a}$ & $21,23 \pm 9,16 b$ & $26,66 \pm 0,37 a$ & $27,62 \pm 0,87 \mathrm{a}$ \\
\hline $\mathrm{L}^{*}$ & $43,81 \pm 3,84 a$ & $42,20 \pm 1,32 \mathrm{a}$ & $41,76 \pm 0,52 \mathrm{a}$ & $42,72 \pm 2,03 \mathrm{a}$ \\
\hline$a^{*}$ & $7,00 \pm 0,28 \mathrm{a}$ & $7,05 \pm 0,62 \mathrm{a}$ & $7,90 \pm 0,42 \mathrm{a}$ & $6,93 \pm 0,35 \mathrm{a}$ \\
\hline$b^{*}$ & $23,60 \pm 2,73 a$ & $22,07 \pm 1,95 \mathrm{a}$ & $21,43 \pm 0,64 a$ & $22,29 \pm 1,70 \mathrm{a}$ \\
\hline Firmeza $(\mathrm{N})$ & $3,05 \pm 0,03 b$ & $4,01 \pm 0,15 \mathrm{a}$ & $2,92 \pm 0,22 b$ & $3,05 \pm 0,33 b$ \\
\hline Adesividade $\left(\mathrm{N} \mathrm{s}^{-1}\right)$ & $-1,33 \pm 0,35 \mathrm{a}$ & $-1,27 \pm 0,37 \mathrm{a}$ & $-1,62 \pm 0,20 \mathrm{a}$ & $-1,00 \pm 0,21 \mathrm{a}$ \\
\hline \multirow[t]{2}{*}{ Aceitação (nota) } & $6,2 \pm 1,75 \mathrm{a}$ & $6,1 \pm 2,08 \mathrm{a}$ & $6,3 \pm 1,86 a$ & $6,0 \pm 1,97 \mathrm{a}$ \\
\hline & \multicolumn{4}{|c|}{ Doce em massa de umbu maduro } \\
\hline $\mathrm{pH}$ & $3,54 \pm 0,08 \mathrm{a}$ & $3,55 \pm 0,10 \mathrm{a}$ & $3,41 \pm 0,17 \mathrm{a}$ & $3,33 \pm 0,30 \mathrm{a}$ \\
\hline Acidez titulável (\% em ácido cítrico) & $0,39 \pm 0,02 \mathrm{a}$ & $0,44 \pm 0,06 \mathrm{a}$ & $0,56 \pm 0,12 \mathrm{a}$ & $0,66 \pm 0,28 \mathrm{a}$ \\
\hline Sólidos solúveis totais $\left({ }^{\circ} \mathrm{Brix}\right)$ & $72,83 \pm 0,29 \mathrm{a}$ & $72,50 \pm 0,50 b$ & $75,33 \pm 0,76 \mathrm{a}$ & $73,67 \pm 0,58 \mathrm{a}$ \\
\hline Atividade de Água (aw) & $0,79 \pm 0,01 \mathrm{ab}$ & $0,80 \pm 0,01 \mathrm{a}$ & $0,75 \pm 0,01 \mathrm{c}$ & $0,76 \pm 0,02 \mathrm{cb}$ \\
\hline Açúcares não redutores (\%) & $36,56 \pm 2,05 b$ & $41,16 \pm 0,42 \mathrm{a}$ & $40,35 \pm 0,01 \mathrm{a}$ & $40,96 \pm 1,35 \mathrm{a}$ \\
\hline Açúcares redutores & $26,85 \pm 1,24 \mathrm{ab}$ & $19,46 \pm 0,18 b$ & $35,79 \pm 2,02 \mathrm{a}$ & $27,70 \pm 1,02 \mathrm{ab}$ \\
\hline $\mathrm{L}^{*}$ & $42,77 \pm 0,81 \mathrm{a}$ & $42,49 \pm 2,19 a$ & $42,92 \pm 0,23 \mathrm{a}$ & $42,23 \pm 2,76 a$ \\
\hline$a^{*}$ & $6,35 \pm 0,51 b$ & $5,46 \pm 0,49 \mathrm{c}$ & $8,19 \pm 0,18 \mathrm{a}$ & $8,59 \pm 1,38 \mathrm{a}$ \\
\hline $\mathrm{b}^{*}$ & $20,84 \pm 0,73 a$ & $19,83 \pm 0,87 \mathrm{a}$ & $19,21 \pm 0,41 \mathrm{a}$ & $19,56 \pm 0,22 \mathrm{a}$ \\
\hline Firmeza $(\mathrm{N})$ & $2,39 \pm 0,47 \mathrm{~b}$ & $4,01 \pm 0,15 \mathrm{a}$ & $2,68 \pm 0,49 b$ & $2,55 \pm 0,89 \mathrm{~b}$ \\
\hline Adesividade $\left(\mathrm{N} \mathrm{s}^{-1}\right)$ & $-1,32 \pm 0,14 a$ & $-0,99 \pm 0,14 \mathrm{a}$ & $-1,0 \pm 0,42 \mathrm{a}$ & $-1,08 \pm 0,14 \mathrm{a}$ \\
\hline Aceitação (nota) & $6,7 \pm 1,74 \mathrm{a}$ & $6,7 \pm 1,93 a$ & $6,2 \pm 1,83 \mathrm{a}$ & $6,5 \pm 1,94 \mathrm{a}$ \\
\hline
\end{tabular}

${ }^{(1)}$ Médias \pm desvio-padrão, seguidas por letras iguais, não diferem entre si pelo teste de Tukey, a 5\% de probabilidade; tratamentos relativos ao doce de umbu verde: F1, 0,3\% de goma xantana; F2, $5 \%$ de xarope de glicose e $0,3 \%$ de goma xantana; F3, 0,5\% de amido modificado; F4, 5\% de xarope de glicose e $0,5 \%$ de amido modificado; tratamentos relativos ao doce de umbu maduro: F1, apenas correção de pH; F2, 0,5\% de pectina; F3, 0,3\% de goma xantana; F4, 0,5\% de amido modificado e $5 \%$ de xarope de glicose. 
e goma xantana, nessa formulação, contribuiu para o aumento da firmeza do doce. Segundo Evageliou et al. (2000), o xarope de glicose tem maior interação com a água do sistema e menor interação com a pectina, o que favorece a obtenção de géis mais rígidos por ligações intermoleculares de pectina. Resultados similares ao presente trabalho foram obtidos por Policarpo et al. (2003b), pela incorporação de $10 \%$ de xarope de glicose às formulações com $5 \%$ de pectina. Os açúcares redutores foram significativamente menores na formulação $F 2$, o que significa um menor grau de hidrólise dos açúcares totais (30\%), em relação à formulação $\mathrm{F} 1$, o que também contribuiu para o aumento da firmeza (Jackix, 1988).

Em relação às características físico-químicas e físicas de doces em massa de umbu maduro, observou-se que a adição de pectina contribuiu para o aumento significativo da firmeza na formulação F2, em relação às demais, que foram similares entre si (Tabela 1). Esses resultados corroboram os obtidos por Soares Junior et al. (2003), os quais verificaram que o aumento de 1 para $1,4 \%$ de pectina de alto teor de metoxilação resultou em doces mais firmes, em massa de manga, na mesma concentração final atingida ( $\left.74^{\circ} \mathrm{Brix}\right)$. Resultados similares foram obtidos por Dervisi et al. (2001), ao adicionar proporções crescentes deste mesmo tipo pectina até 5\%, a geléias de morango processadas em sistemas de alta pressão. O grau de inversão da sacarose, em relação aos açúcares totais, foi menor (32\%) em relação às demais formulações (acima de 40\%), o que também contribuiu para o aumento da firmeza.

Quanto à cor, a adição de pectina reduziu o valor de $a^{*}$ na F1, mas as formulações com adição de goma xantana, amido e glicose apresentaram tonalidade mais avermelhada (Tabela 1).

A atividade de água foi menor para doces com maior conteúdo de sólidos totais, resultado semelhante ao relatado por Soares Junior et al. (2003), que estudaram o perfil texturométrico de doces de manga, e por Policarpo et al. (2003a), que avaliaram os efeitos de adição de pectina e xarope de glicose sobre parâmetros físico-químicos de doces de polpa de umbu verde.

As notas médias de aceitação, atribuídas pelos consumidores, para as formulações de doces em massa de umbu verde e maduro, foram entre 6 (gostei ligeiramente) e 7 (gostei moderadamente), na escala hedônica utilizada, apesar de apenas 30\% dos consumidores conhecerem o fruto, e seu consumo ser baixo na região onde o teste foi realizado (56\% nunca ou quase nunca consumiram). Não houve diferença significativa $(p>0,05)$ entre as notas médias de aceitação, atribuídas pelos consumidores, para as formulações de doces em massa de umbu verde e maduro (Tabela 1).

Pelos histogramas de distribuição de freqüência de notas de aceitação, atribuídas pelos consumidores para as formulações de doces em massa, observou-se que a formulação F2 (5\% xarope de glicose e $0,3 \%$ goma xantana) e a formulação F3 (0,5\% amido modificado), de doces em massa de umbu verde, apresentaram maior frequiência de notas 7 a 9. Resultados semelhantes foram observados para a formulação F1 (apenas, correção de pH) e F2 (0,5\% pectina) do doce de umbu maduro (Figura 1). No trabalho de Policarpo (2003a), as
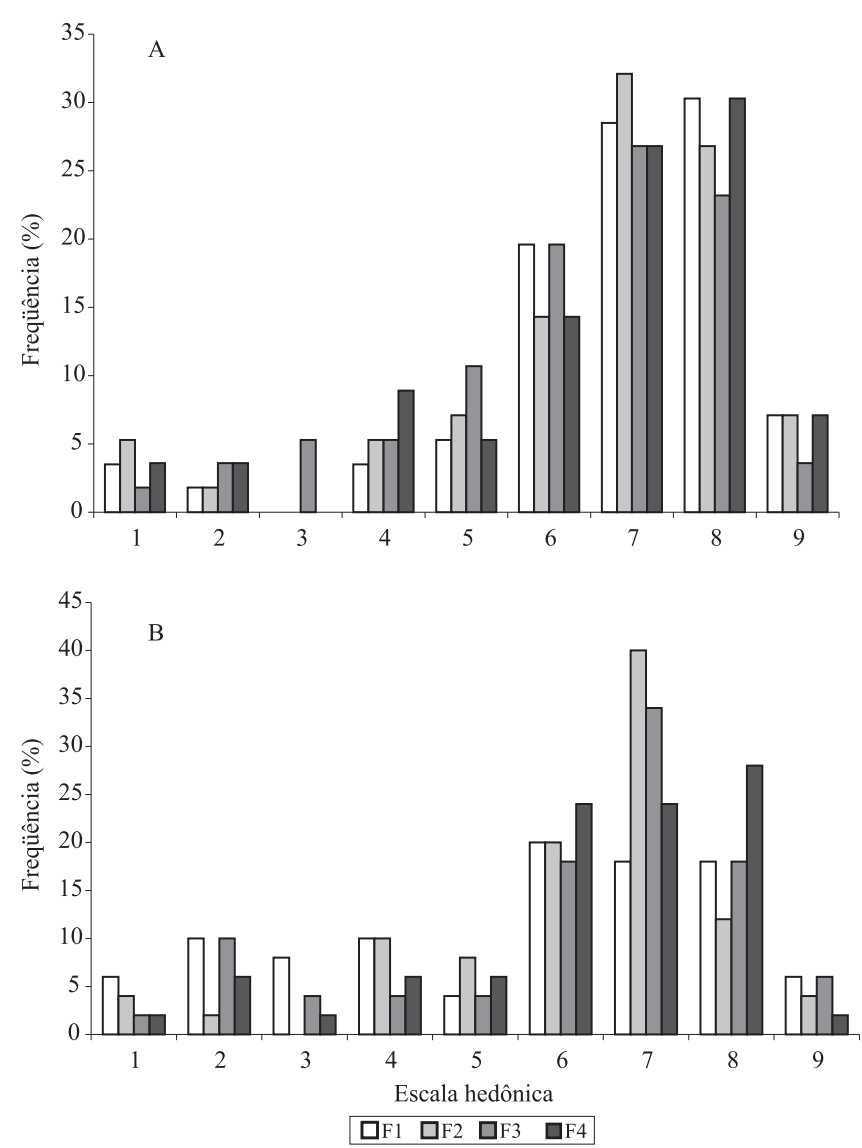

Figura 1. Histograma de distribuição de freqüência de notas de aceitação, atribuídas pelos consumidores, às formulações de doces em massa de umbu verde (A) e maduro (B). Tratamentos relativos ao doce de umbu verde: F1, 0,3\% de goma xantana; F2, 0,3\% de goma xantana e 5\% de xarope de glicose; F3, 0,5\% de amido modificado; F4, $0,5 \%$ de amido modificado e $5 \%$ de xarope de glicose. Tratamentos relativos ao doce de umbu maduro: F1, com correção de $\mathrm{pH} ; \mathrm{F} 2,0,5 \%$ de pectina; F3, 0,3\% de goma xantana; F4, 0,5\% de amido modificado e $5 \%$ de xarope de glicose. 
formulações de doce de umbu verde com adição de pectina e xarope de glicose apresentaram a maior frequiência da nota 8 , atribuída pelos consumidores.

\section{Conclusões}

1. As formulações de doce em massa de umbu verde, com adição de 5\% de xarope de glicose e $0,3 \%$ de goma xantana, e de doce em massa de umbu maduro com $0,5 \%$ de pectina apresentam maior firmeza.

2. Os consumidores residentes no Rio de Janeiro aceitam as formulações de doces em massa de umbu verde e maduro.

\section{Referências}

ABIA. Associação Brasileira das Indústrias de Alimentação. Compêndio de legislação dos alimentos: consolidação das normas e padrões para alimentos. São Paulo: ABIA, 2001. 2v.

ALBUQUERQUE, J.P. Fatores que influem no processamento de geléias e geleiadas de frutas. Boletim da Sociedade Brasileira de Ciência e Tecnologia de Alimentos, v.31, p.1-8, 1997.

Association of Official Analytical Chemists. Official methods of analysis of the Association of Analytical Chemists. Washington: AOAC, 1992. 1015p.

CAMPOS, A.M.; CÂNDIDO, L.M.B. Formulação e avaliação físico-química e reológica de geléias de baixo teor de sólidos solúveis com diferentes adoçantes e edulcorantes. Ciência e Tecnologia de Alimentos, v.15, p.268-278, 1995.

CAVAlCANTI, N.B.; RESENDE, G.M.; BRITO, L.T. Processamento do fruto do umbuzeiro (Spondia tuberosa Arruda Câmara). Ciência e Agrotecnologia, v.24, p.252-259, 2000.

DERVISI, P.; LAMB, J.; ZABETAKIS, I. High pressure processing in jam manufacture: effects on textural and colour properties. Food Chemistry, v.73, p.85-91, 2001.

EVAGELIOU, V.; RICHARDSON, R.K.; MORRIS, E.R. Effect of $\mathrm{pH}$, sugar type and thermal annealing on high-methoxy pectin gels. Carbohydrate Polymers, v.42, p.245-259, 2000.

FENNEMA, O.R. Química de los alimentos. Zaragoza: Ed. Acríbia, 1993. 1095p.

GARCIA, A.E.B. Mudança tecnológica e competitividade: a indústria de doces e conservas de frutas. São Paulo: Scortecci, 2002. 295p.
IBGE. Produção da extração vegetal e da silvicultura, v.18, p.1-43, 2003. Disponível em: http://www.ibge.gov.br/home/ estatistica/economia/pevs/2003/pevs2003.pdf. Acesso em: ago. 2006.

JACKIX, M.H. Doces, geléias e frutas em calda. São Paulo: Ícone, 1988. 172p.

MACFIE, H.J.; BRATCHELL, N.; GREENHOFF, K.; VALLIS, L. Designs to balance the effect of order of presentation and firstorder-carry-over effects in hall tests. Journal of Sensory Studies, v.4, p.129-148, 1989.

MAO, R.; TANG, J.; SWANSON, B.G. Water holding capacity and microstructure of gellan gels. Carbohydrate Polymers, v.46, p.365-371, 2001.

MEIlGAARD, M.; CIVILle, G.V.; CARR, B.T. Sensory Evaluation Techniques. 3.ed. Boca Raton: CRC Press, 1999. 354p. PIMENTEL-GOMES, F. Curso de estatística experimental. São Paulo: Nobel, 1999. 467p.

PINTO, P.R.; BORGES, S.V.; CAVALCANTI, N.B.; OLIVEIRA, V.M.; DELIZA, R. Efeito do processamento de doce em massa de umbu verde e maduro sobre sua composição e aceitação. Revista Brasileira de Alimentos e Nutrição, v.12, p.45-53, 2001.

POLICARPO, V.M.N. Estudo da conservação de doce em massa de polpa de umbu (Spondias tuberosa Arruda Câmara) no estádio de maturação verde. 2002. 105p. Dissertação (Mestrado) Universidade Federal Rural do Rio de Janeiro, Seropédica.

POLICARPO, V.M.N.; ENDO, E.; FARIA, R.Q.; ANJOS, V.; BORGES, S.V.; GREGÓRIO, S.R.; CAVALCANTE, N. Efectos de aditivos sobre el color, textura y aceptación del dulce de umbu (Spondias tuberosa, Arr. Cam.) verde. Alimentaria, n.346, p.111-116, 2003b.

POLICARPO, V.M.N.; RESENDE, J.; ENDO, E.; MARCUSSI, B.; CASTRO, F.T.; JORGE, E.C.; BORGES, S.V.; CAVALCANTE, N.B. Aprovechamiento de la pulpa de "umbu" (Spondias tuberosa, Arr. Cam.) verde como alternativa para la producción de dulces en masa. Alimentaria, n.344, p.75-78, 2003a.

RENARD, D.; VAN DE VELDE, F.; VISSCHERS, R.W. The gap between food gel structure, texture and perception. Food Hydrocolloids, v.20, p.423-431, 2006.

SOARES JUNIOR, A.M.; MAIA, A.B.R.A.; NELSON, D.L. Estudo do efeito de algumas variáveis de fabricação no perfil texturométrico do doce de manga. Ciência e Tecnologia de Alimentos, v.23, p.76-80, 2003.

STONE, H.; SIDEL, J. Sensory evaluation practices. 3.ed. New York: Academic Press, 2004. 377p. 